\title{
Yoga for bronchial asthma: a controlled study
}

\author{
R NAGARATHNA, H R NAGENDRA
}

\begin{abstract}
Fifty three patients with asthma underwent training for two weeks in an integrated set of yoga exercises, including breathing exercises, suryanamaskar, yogasana (physical postures), pranayama (breath slowing techniques), dhyana (meditation), and a devotional session, and were told to practise these exercises for 65 minutes daily. They were then compared with a control group of 53 patients with asthma matched for age, sex, and type and severity of asthma, who continued to take their usual drugs. There was a significantly greater improvement in the group who practised yoga in the weekly number of attacks of asthma, scores for drug treatment, and peak flow rate.

This study shows the efficacy of yoga in the long term management of bronchial asthma, but the physiological basis for this beneficial effect needs to be examined in more detail.
\end{abstract}

\section{Introduction}

Yoga has been used to treat patients with asthma for over 50 years in yoga centres in India. Goyeche et al and several other workers have shown convincing evidence of the beneficial effects of yoga in patients with bronchial asthma.$^{1-6}$ Most of these studies were short term, performed without controls, or qualitative but based on subjective judgments. Our earlier investigation clearly indicated the short term (two to four weeks) benefits of yoga, as established by standard controlled studies of large numbers of patients who underwent yogic training as outpatients. ' Prospective long term studies using standardised research procedures are, however, unavailable.

It is well known that the clinical course of a disease like chronic bronchial asthma is highly variable, being subject to many known

\footnotetext{
Vivekananda Kendra Yoga Therapy and Research Centre, Malleswaram Bangalore 560003

R NAGARATHNA, MD, MRCP, consultant physician

H R NAGENDRA, ME, PHD, yoga secretary

Correspondence to: Dr Nagarathna.
}

and unknown factors. We carried out this long term study with matched controls to ascertain whether yoga could have a lasting influence on the course of the disease.

\section{Patients and methods}

Table I shows details of the 106 patients with established bronchial asthma satisfying the clinical criteria of Crofton and Douglas ${ }^{8}$ and Shivpuri ${ }^{9}$ who were included in this study. The age range was $9-47$ years with a mean of $26 \cdot 4$ years. There were 15 women in each group. Fifty three pairs of patients matched for age and sex and type, severity, and duration of asthma were selected from a bigger group who came to our outpatient clinic for yoga

TABLE I-Details of patients

\begin{tabular}{|c|c|c|}
\hline 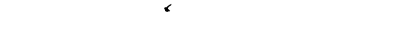 & Control group & Yoga group \\
\hline No of patients $\star$ & 53 & 53 \\
\hline Men & 38 & 38 \\
\hline Women & 15 & 15 \\
\hline Mean age (range) ${ }^{\star}$ & $26.41(9-47)$ & $26 \cdot 36(9-47)$ \\
\hline Mean severity score for asthma (range $)^{\star}$ & $1.45(0-3)$ & $1 \cdot 45(0-3)$ \\
\hline No with seasonal asthma ${ }^{\star}$ & 33 & 33 \\
\hline No with perennial asthma ${ }^{\star}$ & 20 & 20 \\
\hline Mean weekly No of attacks (range) & $3.08(0-7)$ & $3.01(0-7)$ \\
\hline Mean weekly drug treatment score (range) & $10 \cdot 26(0-49)$ & $6 \cdot 22(0-21)$ \\
\hline Mean peak flow rate $(1 / \mathrm{min})$ (range) & $264 \cdot 2(60-580)$ & $290 \cdot 1(80-690)$ \\
\hline
\end{tabular}

${ }^{\star}$ Groups matched for these variables.

therapy. One from each pair was randomly selected for training in yoga, and the other served as a control.

Although all 106 patients were equally motivated to take up yoga, the 53 randomly allocated patients willingly served as controls. They continued taking their usual drugs during the study.

All techniques of measurement, the length of each interview, and the people recording the data were the same for both groups. The yoga group attended a training programme of two and a half hours daily from 1800 to 2030 after work for two weeks. They were introduced to an integrated programme of the following selected yoga exercises.

Breathing exercises (five minutes)-five types of rhythmic, comfortable breathing techniques associated with simple hand and body movements.

Sithilikarana, vyayama, and suryanamaskar (five minutes)-Yoga exercises to loosen the joints.

Yogasanas-(a) General yogasanas (20 minutes). Simple physical postures (in the standing, sitting, prone, and supine positions), performed 
with smooth, comfortable bending movements and specific slow breathing procedures. The asana practices end with the subject maintaining the final posture with the body relaxed. (b) Savasana (10 minutes). Deep relaxation to relax the muscles regionally followed by conscious slowing of breathing and calming of the mind.

Pranayama (10 minutes)-Four types of special breathing techniques performed with comfortable, slow, deep breathing.

Meditation and devotional session (15 minutes)-Slow mental chanting of the syllable "OM," leading to the slowing of mental activity. The devotional session was meant to harness the emotions, resulting in a feeling of freedom.

Kriyas (weekly)-Traditional voluntary nose and stomach wash techniques (neti and vaman dhouti) followed by Savasana.

Lectures and discussions-These were based on yoga philosphy and therapy.

We instructed 53 patients to continue the 65 minutes of yoga daily during the follow up period. For the purposes of analysis those patients who stopped the practices or did not practise for more than 16 days each month were eliminated from the study, although we continued to record their progress. Twenty five patients dropped out of the study: seven after six months of follow up, seven after 12 months, two after 18 months, four after 24 months, and five after 30 months. All patients reported for check ups at intervals of six months. The frequency of visits and the relationship between doctor and patient were the same for both groups.

At the initial interview patients were instructed to keep a diary. They were told to record each attack of airway obstruction, its severity, and the dosage of the drugs they consumed. They continued to take prescribed bronchodilators during the study. When they noticed an improvement or deterioration in their asthma they were permitted to change their dosage as required, and they recorded this in their diaries. Any change in the brand of drug, however, was decided by the doctor. At each of the follow up visits information from patients' diaries and from clinical examinations was recorded. The mean weekly number of attacks for each period of follow up was calculated. Severity of attacks was graded: $1=$ mild, but did not disturb sleep or daily routine; 2 =moderate, disturbed sleep and daily routine and was relieved by oral drugs; $3=$ severe, required injection or admission to hospital. We obtained a score for drug treatment by calculating the mean number of bronchodilator tablets and injections taken each week for each period of follow up. None of the patients used inhalers. Peak expiratory flow rate was obtained by recording the best of three attempts on a mini Wright peak flow meter.

\section{Results}

Table II shows the results of the study. Comparison of the two groups using Student's $t$ test showed a highly significant improvement in the number of attacks per week and drug treatment scores in the patients who practised yoga. Because of large fluctuations in the mean, the standard

TABLE II-Results of Students' paired t test for mean differences between values before and after 54 months' follow up for the two groups of 53 patients

\begin{tabular}{|c|c|c|c|c|c|}
\hline \multirow[b]{2}{*}{ Variables } & \multirow[b]{2}{*}{ Group } & \multirow[b]{2}{*}{$\begin{array}{l}\text { Mean (SD) } \\
\text { initial value }\end{array}$} & \multirow[b]{2}{*}{$\begin{array}{l}\text { Mean (SD) } \\
\text { final value }\end{array}$} & \multicolumn{2}{|c|}{ Significance } \\
\hline & & & & $\begin{array}{c}\text { Difference } \\
\text { between initial } \\
\text { and final values }\end{array}$ & $\begin{array}{c}\text { Difference } \\
\text { between groups }\end{array}$ \\
\hline No of attacks of asthma/week & $\left\{\begin{array}{l}\text { Control } \\
\text { Yoga }\end{array}\right.$ & $\begin{array}{ll}2.9 & (3.01) \\
3.55 & (2.98)\end{array}$ & $\begin{array}{ll}2 \cdot 1 & (2.7) \\
0.83 & (2.49)\end{array}$ & $\left.\begin{array}{l}2 \cdot 578^{\star \star} \\
4 \cdot 827^{\star \star \star}\end{array}\right\}$ & $2 \cdot 825^{\star \star}$ \\
\hline Severity score & $\left\{\begin{array}{l}\text { Control } \\
\text { Yoga }\end{array}\right.$ & $\begin{array}{ll}1.6 & (0.75) \\
1.47 & (0.66)\end{array}$ & $\begin{array}{ll}1.05 & (0.85) \\
0.75 & (0.8)\end{array}$ & $\left.\begin{array}{l}4 \cdot 006^{\star \star} \\
5 \cdot 016^{\star \star}\end{array}\right\}$ & $0 \cdot 369$ (NS) \\
\hline Drug treatment score & $\left\{\begin{array}{l}\text { Control } \\
\text { Yoga }\end{array}\right.$ & $\begin{array}{rr}6 \cdot 22 & (7 \cdot 18) \\
10 \cdot 26 & (13 \cdot 16)\end{array}$ & $\begin{array}{ll}7.9 & (9.9) \\
2.08 & (4.09)\end{array}$ & $\left.\begin{array}{l}0.556(\mathrm{NS}) \\
4.964^{\star \star}\end{array}\right\}$ & $3 \cdot 152^{\star \star}$ \\
\hline Peak flow rate $(1 / \mathrm{min}) \dagger$ & $\left\{\begin{array}{l}\text { Control } \\
\text { Yoga }\end{array}\right.$ & $\begin{array}{lc}264 \cdot 2 & (117 \cdot 2) \\
290 \cdot 1 & (93 \cdot 1)\end{array}$ & $\begin{array}{l}290 \cdot 8 \quad(12 \cdot 2) \\
362 \cdot 8 \quad(107 \cdot 6)\end{array}$ & $\left.\begin{array}{l}4 \cdot 065^{\star \star} \\
7 \cdot 336^{\star \star}\end{array}\right\}$ & $1 \cdot 817^{\star}$ \\
\hline
\end{tabular}

TABLE III-Median test with $\chi^{2}$ evaluation of significance of difference in variables between yoga and control groups before and after 54 months' follow up

\begin{tabular}{|c|c|c|}
\hline \multirow[b]{2}{*}{ Variable } & \multicolumn{2}{|c|}{$\chi^{2}$ value } \\
\hline & Initial & Final \\
\hline $\begin{array}{l}\text { No of attacks of asthma/week } \\
\text { Severity score } \\
\text { Drug treatment score } \\
\text { Peak flow rate }\end{array}$ & $\begin{array}{l}0 \cdot 06 \\
0 \cdot 149 \\
l \cdot 1020 \\
0 \cdot 0448\end{array}$ & $\begin{array}{l}5 \cdot 665^{\star} \\
1 \cdot 89 \\
4 \cdot 56^{\star} \\
3 \cdot 87^{\star}\end{array}$ \\
\hline
\end{tabular}

TABLE IV-Numbers of patients who changed their drug treatment

\begin{tabular}{|c|c|c|c|c|}
\hline & Stopped & Reduced & No change & Increased \\
\hline $\begin{array}{l}\text { Control group } \\
\text { Yoga group }\end{array}$ & $\begin{array}{l}23 \\
30\end{array}$ & $\begin{array}{r}9 \\
12\end{array}$ & $\begin{array}{l}7 \\
3\end{array}$ & $\left.\begin{array}{r}14 \\
8\end{array}\right\} \chi^{2}=4 \cdot 48^{\star}$ \\
\hline
\end{tabular}

deviation was similar to the mean for many of the values in table II. A nonparametric median test with a $\chi^{2}$ evaluation was therefore used to determine significance. Table III shows the results and confirms that there were highly significant improvements in the yoga group compared with the controls. A highly significant difference in peak flow rate was also shown by the nonparametric test.

Table IV shows the numbers of patients who changed their drug treatment in both groups; yoga had a significantly beneficial effect $(p<0.01)$.

Table $\mathrm{V}$ shows the distribution of the initial and final mean values for drug treatment score and peak flow rate in the yoga and control groups over the months of follow up. In the yoga group the drug treatment score fell considerably and the peak flow rate increased (to a greater extent than that in the controls).

\section{Discussion}

As care was taken to match the two groups for age and sex and type, severity, and duration of asthma, we can attribute the improvement seen in the variables measured in the 53 patients in the

TABLE V_-Variations in mean scores for drug treatment and peak flow rate after each six month period of follow up

\begin{tabular}{|c|c|c|c|c|c|c|c|c|c|}
\hline & \multirow[b]{2}{*}{ Group } & \multirow[b]{2}{*}{ Initial } & \multicolumn{7}{|c|}{ Periods of follow up } \\
\hline & & & 6 months & 12 months & 18 months & 24 months & 30 months & 36 months & 54 months \\
\hline $\begin{array}{l}\text { Mean drug treatment score } \\
\text { Peak flow rate }(1 / \mathrm{min})\end{array}$ & $\begin{array}{l}\text { Control } \\
\text { Yoga } \\
\text { Control } \\
\text { Yoga }\end{array}$ & $\begin{array}{c}10 \cdot 26 \\
6 \cdot 22 \\
264 \cdot 2 \\
290 \cdot 1\end{array}$ & $\begin{array}{c}2.875 \\
0.428 \\
291.25 \\
371.66\end{array}$ & $\begin{array}{c}10 \cdot 66 \\
5 \cdot 444 \\
174 \cdot 5 \\
339 \cdot 375\end{array}$ & $\begin{array}{l}0 \cdot 666 \\
7 \cdot 0 \\
190 \\
236\end{array}$ & $\begin{array}{l}1 \cdot 875 \\
1 \cdot 166 \\
222 \cdot 5 \\
372 \cdot 5\end{array}$ & $\begin{array}{c}14 \cdot 5 \\
1 \cdot 20 \\
236 \cdot 66 \\
370 \cdot 0\end{array}$ & $\begin{array}{c}7 \cdot 0 \\
2 \cdot 0 \\
308 \cdot 75 \\
410 \cdot 0\end{array}$ & $\begin{array}{c}9 \cdot 0 \\
3 \cdot 111 \\
320.62 \\
348 \cdot 75\end{array}$ \\
\hline
\end{tabular}


yoga group to the regular practice of yoga. The considerable reduction in their drug treatment score in contrast with a nonsignificant increase in intake of drugs in the control group strengthens this view, as do the significant differences between the groups in the number of attacks per week and peak flow rate.

McFadden clearly showed that the responsiveness of airways is noticeably increased in patients with asthma, who develop bronchoconstriction in response to smaller quantities of physical, chemical, and pharmacological stimuli than healthy subjects. ${ }^{10} \mathrm{~A}$ complex interplay of several factors-namely, an inherent responsiveness of the smooth muscle to stimuli, an abnormality in autonomic nervous control, and a breakdown in airway defences-may promote bronchial hyper-reactivity. Thus reducing the responsiveness of the tracheobronchial tree could benefit these patients considerably.

Abundant objective data now exist indicating that pyschological factors can interact with the asthmatic diathesis to worsen or improve the course of the disease. The mechanisms of these interactions are complex and not well understood, but psychological factors may affect about half of all patients. Modification of vagal efferent activity seems to affect the calibre of airways. It has been shown that suggestion can actually decrease or increase the effects of pharmacological stimuli on the airways. The role of the psychic factor in inducing or prolonging attacks in acute exacerbations may vary from patient to patient and in individual patients from episode to episode.

Goyeche et al claimed that the psychosomatic imbalance is present in many, if not all patients with asthma. ${ }^{1}$ Suppressed emotion, anxiety, dependence, and extreme self consciousness may all be accompanied by generalised and localised muscle tension, including that of the voluntary respiratory musculature. This increased muscle tension may be a precipitating or concomitant factor that perpetuates and aggravates the asthmatic syndrome.

Yoga seems to stabilise and reduce the excitability of the nervous system. Transcendental meditation (a traditional yogic meditation technique) and Savasana have been clearly shown to be associated with reduced metabolic rate. ${ }^{11}$ Crisan showed a significant reduction in the level of anxiety after the practice of Pranayama, as evidenced by increased skin resistance and a reduction in pulse rate, urinary catecholamine concentration, urinary cholinesterase activity, and anxiety scores. ${ }^{12}$ Several workers have found an increase in alpha synchrony in electroencephalograms taken during transcendental meditation, which points to its stabilising effect on the nervous system. Yoga clearly relaxes the muscles, and this deep physical and mental relaxation associated with the physiological changes seen in our patients after daily yoga seems to have a stabilising effect on bronchial reactivity, thus making the vagal efferents less excitable.

In conclusion, the reduction in psychological hyper-reactivity and emotional instability achieved by yoga can reduce efferent vagal reactivity, which has been recognised as the mediator of the psychosomatic factor in asthma.

\section{References}

1 Goyeche JRM, Abo Y, Ikemi Y. The yoga perspective. Part II. Yoga therapy in the treatment of asthma. I Asthma 1982;19:189-201.

asthma. J Asthma $1982 ; 19: 189-201$. 1967;9:32-41.

1967;9:32-41.
Bhole MV. Rationale of treatment and rehabiliation of asthmatics by yogic methods. Collected papers on yoga. Lonavla, India: Kaivalyadhama, 1975: 106-14.

Erskin J, Schonnel M. Relaxation therapy in bronchial asthma. F Psychosom Res 1979;23:131-9.

Honsberger R, Wilson AF. Transcendental meditation in treating asthma. Respiratory Therapy 1973;3:79-81.

6 Murthy KRJ, Sahaj BK, Silaramaraju P, et al. Effect of pranayama (rechaka, puraka, and kumbhaka) on bronchial asthma- an open study. Lung India 1983;5:187-91.

7 Nagarathna R, Nagendra HR. Studies on bronchial asthma 1981-84. Bangalore, India: Vivekananda Kendra Yoga Therapy and Research Centre. (Reports 1-4, 8-11.)

8 Crofton J, Douglas A. Respiratory diseases. 2nd ed. Oxford: Blackwell Scientific Publications, 1975:429.

9 Shivpuri DN. Studies on methods of clinical research in bronchial asthma and allied conditions. Aspects of Allergy and Applied Immunology 1974;7:15-35.

$10 \mathrm{McF}$ adden ER Pathogenesis of asthma. F Allergy Clin Immunol 1984;73:413-22.

$11 \mathrm{Patel} \mathrm{CH}$. Twelve month follow up of yoga and biofeedback in the management of hypertension. Lancet 1975;i:62-3.

12 Crisan HG. Pranayama in anxiety neurosis - a pilot study. Heidelberg: University of Heidelberg, 1984. (PhD dissertation.)

(Accepted 8 August 1985)

\title{
Treatment of homozygous familial hypercholesterolaemia: an informative sibship
}

\author{
RICHARD WEST, PENELOPE GIBSON, JUNE LLOYD
}

\begin{abstract}
In a family in which both parents had the heterozygous form of familial hypercholesterolaemia four of the children had the homozygous form. The three oldest homozygous children, two of whom did not receive any treatment and in one of whom treatment did not lower the plasma cholesterol concentration, developed xanthomas in early childhood and died aged 3, 9, and 10 years. The fourth homozygous child was treated with diet and drugs from the age of 1 and at the age of 15 had no xanthomas, no clinical evidence of heart disease, and a virtually normal coronary
\end{abstract}

\footnotetext{
Department of Child Health, St George's Hospital Medical School, London SW17

RICHARD WEST, MD, FRCP, senior lecturer

PENELOPE GIBSON, MRCP, lecturer

JUNE LLOYD, MD, FRCP, professor

Correspondence to: Dr West.
}

angiogram. His plasma cholesterol concentration was reduced by about $30 \%$ but remained considerably raised.

It is concluded that treatment, if started before atherosclerosis develops, can delay the onset of atheroma and coronary heart disease even though normal plasma cholesterol concentrations are not achieved.

\section{Introduction}

Familial hypercholesterolaemia is dominantly inherited, and heterozygotes have an increased risk of coronary heart disease in adult life. Homozygotes have extremely high plasma cholesterol concentrations and die of coronary heart disease in childhood or early adult life.' Treatment of homozygotes is difficult. Normal cholesterol concentrations are unlikely to be achieved, and uncertainty exists over whether coronary atherosclerosis can be prevented..$^{23}$

We report on a family containing four siblings homozygous for the disease. The progress of the youngest contrasted with that of the other affected siblings, suggesting that prevention of atherosclerosis is possible. 